\title{
Correction to: Patterns of species co-occurrence in a diverse Eastern Himalayan montane carnivore community
}

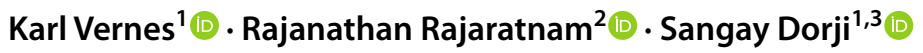

Published online: 12 January 2022

(c) The Author(s), under exclusive licence to Mammal Research Institute Polish Academy of Sciences 2022

\section{Correction to: Mammal Research}

https://doi.org/10.1007/s13364-021-00605-3

In the original published version of the above article, the co-author's surname the letter "i" was missing. The name should been Sangay Dorji instead of Sangay Dorj. The correct name is now presented correctly above.

The original article has been corrected.

Publisher's note Springer Nature remains neutral with regard to jurisdictional claims in published maps and institutional affiliations.

The original article can be found online at https://doi.org/10.1007/ s13364-021-00605-3.

Karl Vernes

kvernes@une.edu.au

Rajanathan Rajaratnam

rrajarat@une.edu.au

Sangay Dorji

drsangaydorji@gmail.com

1 Ecosystem Management, University of New England, Armidale, NSW 2351, Australia

2 Geography \& Planning, University of New England, Armidale, NSW 2351, Australia

3 Department of Forests and Park Services, Thimphu, Bhutan 